\title{
Commercial Mortgage Prepayments Under Heterogeneous Prepayment Penalty Structures
}

Authors Qiang Fu, Michael LaCour-Little and

Kerry D. Vandell

Abstract

\begin{abstract}
Much of the literature on pricing commercial mortgages and commercial mortgage-backed securities has assumed homogeneity in prepayment penalty structure. This study provides evidence that such an assumption is inappropriate and examines the effect of penalty structures observed in actual contracts. After conducting preliminary simulations, hazard models estimated from data on 1,165 multifamily mortgage loans are presented to show how empirical prepayment rates vary with alternative penalty structures. While yield maintenance and lockout provisions are relatively more effective than fixed or step down structures in reducing or postponing prepayment, none completely eliminates the risk. The empirical results generally confirm the theoretical findings of Kelly and Slawson (2001).
\end{abstract}

\section{Introduction}

Much attention has been directed toward understanding the performance of commercial, especially multifamily, mortgages, given the dramatic increase in commercial mortgage-backed security (CMBS) issuance and recent pricing and liquidity problems. ${ }^{1}$ Most earlier research (e.g., Titman and Torous, 1989; Kau, Keenan, Muller and Epperson, 1990; Vandell, 1992; Vandell, Barnes, Hartzell, Kraft and Wendt, 1993; and Goldberg and Capone, 1997) focuses on default risk and assumes away prepayment risk, on the view that commercial mortgages contain prepayment penalties, lockouts or yield maintenance provisions that render prepayment unlikely, or fully compensate the lender.

However, a careful empirical look at prepayment exercise among commercial and multifamily mortgages reveals that prepayment does occur and cannot be ignored, especially since it may produce pricing fluctuations an order of magnitude greater than default risk. Prepayment occurs because (1) the assumed penalties do not exist, (2) they exist but are less effective than assumed, or (3) borrowers overexercise prepayment irrationally, perhaps motivated by factors outside the standard model framework. 
Accordingly, more recent research on commercial mortgages (e.g., Abraham and Theobold, 1997; Boyer, Follain, Ondrich and Piccirillo, 1997; Capone and Goldberg, 1998; Daingerfield, 1995; Elmer and Haifdorfer, 1997; Follain, Ondrich and Sinha, 1997; Follain, Huang and Ondrich, 1999; and Kelly and Slawson, 2001) has focused on prepayments. Among these, only Abraham and Theobald and Kelly and Slawson address alternative penalty structures, and the latter only through simulation. This study examines, both theoretically and empirically, using estimation as well as simulation, the extent to which alternative prepayment penalty structures can be expected to-and actually do-affect prepayment exercise among multifamily mortgage borrowers. Results can inform pricing models for both commercial mortgages and their mortgage-backed securities.

The paper is structured follows. First, related past research is reviewed. Next, a simplified option-theoretic model is developed that explicitly incorporates five observed prepayment penalty structures and simulates expected prepayments in a stochastic interest rate environment. Results of the simulation provide explanatory variables used in the subsequent empirical analysis are next presented. The empirical model, data and report results follow. Finally, general conclusions and implications of the results are presented.

\section{Past Research}

Empirical research using single-family data has shown that both default and prepayment options appear to be under-exercised, relative to the predictions of the option-theoretic approach (Quigley and Van Order, 1990, 1995). This has led to debate over the role of transaction costs and the degree of "ruthlessness" among option holders (Vandell, 1995). An alternative view holds that it is trigger events that often prompt default and prepayment and these decisions are only imperfectly related to underlying option values (Riddiough and Thompson, 1993). In the single family market, borrower mobility and institutional constraints that prevent refinancing may provide further explanation, for instance, insufficient equity or impaired credit may constrain prepayments (Peristiani, Bennett, Monsen, Peach and Raiff, 1997; and Green and LaCour-Little, 1999).

Some argue that irrational option exercise may be less an issue in the commercial mortgage market, since investors in income property do not relocate, triggering prepayments, in the way that single-family mortgagors do, though they may have heterogeneous or tax-induced holding period preferences. Moreover, financially sophisticated investors seem more likely to "ruthlessly" exercise their options. Default in commercial mortgages has been thoroughly explored in Vandell (1992) and Vandell, Barnes, Hartzell, Kraft and Wendt (1993), who still find underexercise compared to theoretical model predictions, although at a lower level than Foster and Van Order (1985) find in the single-family market, using similar methodology.

Turning to recent studies of commercial mortgages, Abraham and Theobald (A\&T) (1997) develop a simple prepayment model using a sample of 7,800 
multifamily mortgages owned by Freddie Mac and originated over the period 1984-1990. Following Foster and Van Order's (1985) work in the single-family segment, A\&T find that multifamily has lower prepayment risk at discount coupons and higher prepayment risk at premium coupons (i.e., that multifamily loans have greater interest rate sensitivity compared to single-family). Since their data set includes some variation in prepayment penalties (lockouts, yield maintenance and step down structures), the effect of the prepayment penalty over time may be observed. A\&T describe the function as a "hockey stick" pattern, in which prepayments are close to zero during the lock-out period, then inflecting sharply (to roughly a $45^{\circ}$ angle) once the prepayment penalty period has expired.

Follain, Ondrich and Singha (FO\&S) (1997) consider whether prepayments in the commercial mortgage market are indeed more "ruthless" compared to the singlefamily market. FO\&S use loan-level data on 1,083 multifamily loans originated during 1975-1986 and tracked through 1989 to estimate a mortgage prepayment function. Over the study period, 451 loans prepaid, 20 defaulted and the balance survived. All were subject to a single prepayment penalty, which FO\&S treat as a prepayment-reducing transaction cost, consisting of six months interest if the loan is less than five years old and $1 \%$ of outstanding loan balance thereafter. While they find that their measure for the option value is positive and statistically significant across models, the implied hazard model predicts relatively low values (never exceeding 10\% until loan age exceeds ten years), even when the prepayment option is deep in the money.

Elmer and Haidorfer (E\&H) (1997) focus on prepayments of RTC commercial mortgage-backed securities issued during 1991-1992. E\&H use cross-sectional time series methods to calculate 12-month conditional prepayment rates as of December 1995 in the range of $13 \%-18 \%$, substantially higher than the hazard rate results of FO\&S. These higher rates may be related to the absence of prepayment penalties on these loans or loan seasoning, although E\&H are silent on the topic of prepayment penalties, if any exist.

Capone and Goldberg (1998) use data on Freddie Mac and Fannie Mae cash purchases of 13,338 multifamily mortgage loans originated during the period 1983-1995. They augment their data to create time-varying estimates of vacancy rate and property net operating income. Simulation results show relatively low conditional prepayment rates (never exceeding 10\% annually) for 30-year fully amortized loans even when the option is significantly in the money; however, prepayment rates for 10-year balloons are very high (over 40\%) in periods around the balloon date.

Maxam and Fisher (M\&F) (1998) focus on pricing effects on CMBS issues backed by multiple property types in which lock-outs preclude rate-driven prepayments but in which defaults may produce early return of principal to senior security holders. Among innovations, M\&F use kernel density regression to model security prices as a function of property indices and mortgage rates. M\&F argue that although senior tranches are theoretically immune from prepayment risk, the 
transformation of default to prepayment risk is evident in the pricing relationships generated.

Follain, Huang and Ondrich (1999) examine default and prepayment risk in FHAinsured multifamily loans, using a competing risks-proportional hazards method. They find evidence consistent with the option pricing theory of prepayments but very low rates of prepayment during the initial twenty years of a thirty-year mortgage. This pattern is even more pronounced for those loans in their data that were secured by Section 8 properties, possibly because public subsidy utilization produces a substantial disincentive for prepayment.

Kelly and Slawson (K\&S) (2001) use simulation to address the value of delay in the case of commercial mortgages containing prepayment penalties. Their approach extends the line of research showing a value to delay for both default and prepayment options in the single-family market (Kau and Kim, 1994). Intuitively, an additional cost to exercising an option today is the loss of the right to exercise that same option in the future. $K \& S$ consider a full range of possible prepayment penalties, including permanent, fixed, step-down, yield maintenance and lockouts, but adopt an admittedly simplistic view of default, in which cash flows are proportional to property values and asset values follow a standard diffusion process. $K \& S$ find that time-varying prepayment penalties significantly affect optimal prepayment decisions, since the value of delay differs between static and declining prepayment penalty structures. Among their conclusions, $\mathrm{K} \& \mathrm{~S}$ state that "it is crucial that empirical researchers consider the effect of time-varying prepayment penalties." 2 The empirical effort here follows this prescription.

In summary, both single-family and multifamily research has been hampered by the lack of detailed data that would allow researchers to separate call option exercise from borrower mobility effects (in the single-family area) and detailed information on the nature and extent of prepayment penalties (in the multifamily area). The current research remedies these problems through use of micro-level data on 1,165 multifamily mortgage loans, with heterogeneous prepayment penalties, originated during the period 1991-1996 and observed through April 2000.

\section{Expectations from Option Theory: Simulation Results}

A binomial option-pricing model is solved first, which has been extended to include alternative prepayment penalties. Default risk is excluded for the purposes of the simulation and to focus on prepayments. ${ }^{3}$ The analysis borrows from Tian (1992) and Deng (1997) the method of interest rate simulation. Tian proposes a simplified binomial process to mimic the interest rate processes. This method is later adopted by Deng to replicate the Cox-Ingersoll-Ross (CIR) (1985) interest rate process and then used to evaluate mortgage prepayment and default option values. ${ }^{4}$ Under the CIR assumption, the spot interest rate follows: 


$$
d r=\lambda(\theta-r) d t+\sigma \sqrt{r} d z
$$

where $r$ is the spot interest rate, $\lambda$ is the speed of mean reversion, $\theta$ is the longterm interest rate, $\sigma$ is volatility and $d z$ is a standard Wiener process.

Chan, Karolyi, Longstaff and Sanders (1992) use the generalized method of moments to estimate the parameters of the CIR process. Using data through December 2000, they recently re-estimated the parameters to be: $\lambda=0.2536$; $\theta=0.0715$; and $\sigma=0.0899 .5$ An initial spot rate of $7 \%$ is assumed here. Under this risk-neutral interest rate environment, the value of a 10 -year $7.5 \%$ interestonly balloon mortgage and the value of the prepayment penalty using backward induction along the binomial interest rate tree are computed. The value of the mortgage $V_{0}$ with maturity $m$ at time $t$ is:

$$
\begin{aligned}
V_{m}= & \text { Payment }_{m} \\
V_{t}= & \text { Payment }_{t}+\min \left(P_{t}^{u} * V_{t+1}^{u} * e^{-r(t)}+P_{t}^{d} * V_{t+1}^{d} * e^{-r(t)},\right. \\
& \left.\left(\text { Balance }_{t}+\text { Penalty }_{t}\right)\right) \\
V_{0}= & \min \left(P_{0}^{u} * V_{1}^{u} * e^{-r(0)}+P_{0}^{d} * V_{1}^{d} * e^{-r(0)}\right. \\
& \left.\left(\text { Balance }_{0}+\text { Penalty }_{0}\right)\right),
\end{aligned}
$$

where $P_{t}^{u}$ is the probability the interest rate moves up in the next month at time $t$ and $P_{t}^{d}$ is the probability the interest rate moves down in the next month at time $t$. $V_{t+1}^{u}$ is the value of the mortgage at time $t+1$ if the interest rate moves up from time $t$ to $t+1$, and $V_{t+1}^{d}$ is the value of the mortgage at time $t+1$ if the interest rate moves down from time $t$ to $t+1 . r(t)$ is the spot interest rate and Payment $_{t}$ is the scheduled monthly payment at time $t$. Each month, the borrower evaluates whether it is profitable to exercise its prepayment option by comparing the option exercise price, equaling the outstanding mortgage balance (Balance ${ }_{t}$ ) plus prepayment penalty ( Penalty $_{t}$ ) and the expected present value of the mortgage in the next period. At mortgage maturity $m$, the value of the mortgage is its last payment. The value of the prepayment penalty is the difference between the value of the mortgage with prepayment penalty, and the value of the mortgage with zero prepayment penalty. Hence, the simulation effectively assumes optimal (or "ruthless") exercise of the prepayment option, taking into account the cost (if any) of exercising the option.

To focus on prepayment effects and because the data contained few defaults, ${ }^{6}$ the default option was ignored and included only prepayments. Five different penalty structures are described below: 
1. No prepayment penalty. The base case, with zero transaction cost, which we expect will result in the maximum prepayment rate for a given set of conditions.

2. A lockout, or prohibition against prepayment until time period $t$, which is specified as an infinite prepayment penalty at each point in time and results in zero prepayment under all conditions. If $t=T$, the balloon term of the note, this structure effectively establishes the opposite condition to Equation (1). When $t<T$, there is a temporary lockout, in which prepayment is prohibited only up until time $t$ (this is the usual case with actual contracts). In the simulations here, the magnitude of $t$ is varied: $t=T=10, t=5, t=3$ and $t=1$ year.

3. A fixed prepayment penalty, specified as a percentage of the current outstanding loan balance. Again, the levels and time periods are varied. In the simulations, the levels varied: $\lambda_{p}=5 \%, 3 \%$ and $1 \%$ and $t=T=$ 10 years or $t=5$ years.

4. Step-down prepayment penalty, which resembles the fixed penalty, except that the penalty level drops at intervals toward zero rather than all at once. A step-function is first assumed from level $\lambda_{p}=5 \%$ at the end of year 5 , to $4 \%$ at the end of year 6 , etc., to $1 \%$ at the end of year 9 and zero by the end of year 10 (the balloon). Alternatively, it was assumed that $\lambda_{p}=3 \%$ at the end of year 5 to $2 \%$ at the end of year 6 , to $1 \%$ at the end of year 7 and zero by the end of year 8 .

5. A yield-maintenance formula, in which the penalty is a function of current interest rates, structured to compensate for losses when prepayments occur in a declining rate environment. A variety of such formulae have emerged [see summary in Cheng, Cooper and Huang (1997)]. Note that all are imperfect proxies for "making one whole" as the result of the exercise of prepayment because of implicit assumptions about reinvestment rates. In the simulations, the following formula was used, as contained in actual contracts used by the supplier of the data:

$$
\lambda_{p t}=\left(r_{c}-r_{m t}\right)\left[\left(1-\left(1-r_{m t}\right)^{-n}\right) / r_{m t}\right]
$$

where $\lambda_{p t}=$ prepayment penalty in time $t$ as a fraction of the remaining balance, $r_{c}=1 / 12$ the contract rate on the note, $r_{m t}=1 / 12$ the current Treasury rate for notes of maturity equal to the remaining term to maturity on the note, and $n=$ the remaining term to maturity on the note, in months.

Notice that the yield-maintenance formulation results in a stochastic penalty, ex ante, since interest rates are uncertain, while other penalty amounts are known. This will have an impact on pricing the prepayment option and the probability of prepayment ceteris paribus. 
The results, including both pricing effects and prepayment patterns over time, are summarized in Exhibits 1-3. Note the following:

1. As expected, the absence of any penalty produces the highest prepayment rate. As shown in Exhibit 4, the probability of prepayment prior to term (10 years) is $92.1 \%$ and after five years is $77.8 \%$. The option value is also greatest with no penalty, at $7.2 \%$ of par. The variable pattern of prepayment after month 84 is due to the lumpiness in the simulation procedure.

2. Fixed prepayment penalties over the term also reduce prepayment. As the penalty level increases from $1 \%$ to $5 \%$, rates (relative to that for no prepayment penalty) became progressively lower in the earlier and later years and more "peaked" (Exhibit 1). The cumulative rate of prepayment and value of the prepayment option also decline (Exhibit 4).

3. A fixed prepayment penalty over a term of five years produces a prepayment rate lower than if the penalty was over the full term, and the rate becomes geometrically lower as one approaches the "cliff" (i.e., the end of the penalty term). However, the rate jumps considerably after the penalty term, increasingly so for stronger penalties (Exhibit 1). Although cumulative rates of prepayment were significantly lower than in the case of no prepayment penalty after five years, almost this entire decline was made up by the end of the term. The cumulative rate of prepayment at the end of term was within $10 \%$ of what it would have been with no prepayment penalty, for term penalties up to $5 \%$ (Exhibit 4).

4. The existence of a lockout over the term, likewise, produces no prepayments; hence, zero value for the prepayment option (Exhibit 2). ${ }^{7}$ When the lockout expires prior to the ten-year term of the note, prepayment is delayed until that time. The longer the lockout period, in general, the greater the rate of prepayment that immediately follows. However, timing of prepayment is extended and the cumulative rate of prepayment reduced as lockout term increases (Exhibit 4).

5. Step-down penalties produce complex "sawtooth" patterns (Exhibit 3). Prepayments tend to decline in anticipation of an upcoming drop in the penalty level; then, immediately thereafter, they increase again. These patterns were repeating in the case of successive drops in penalty levels. The drop and subsequent rise was most extreme when the penalty level and drop were both high, such as in the $3-1-0 \%$ penalty structure relative to the $5-4-3-2-1-0 \%$ penalty structure. The cumulative prepayment rates and prepayment option values for step-down penalties displayed in Exhibit 4 suggest that they delay prepayment less than the five-year fixed penalty until after year five. The increase above the fixed-over-term prepayment penalty case after year five, however, is also less than that for the five-year fixed penalty. The net result is a cumulative rate of prepayment and value of the prepayment option that is in between that of the fixed-over-term and the five-year fixed prepayment penalty. 
Exhibit 1 | Conditional Probability of Prepayment for Fixed Penalty Loans

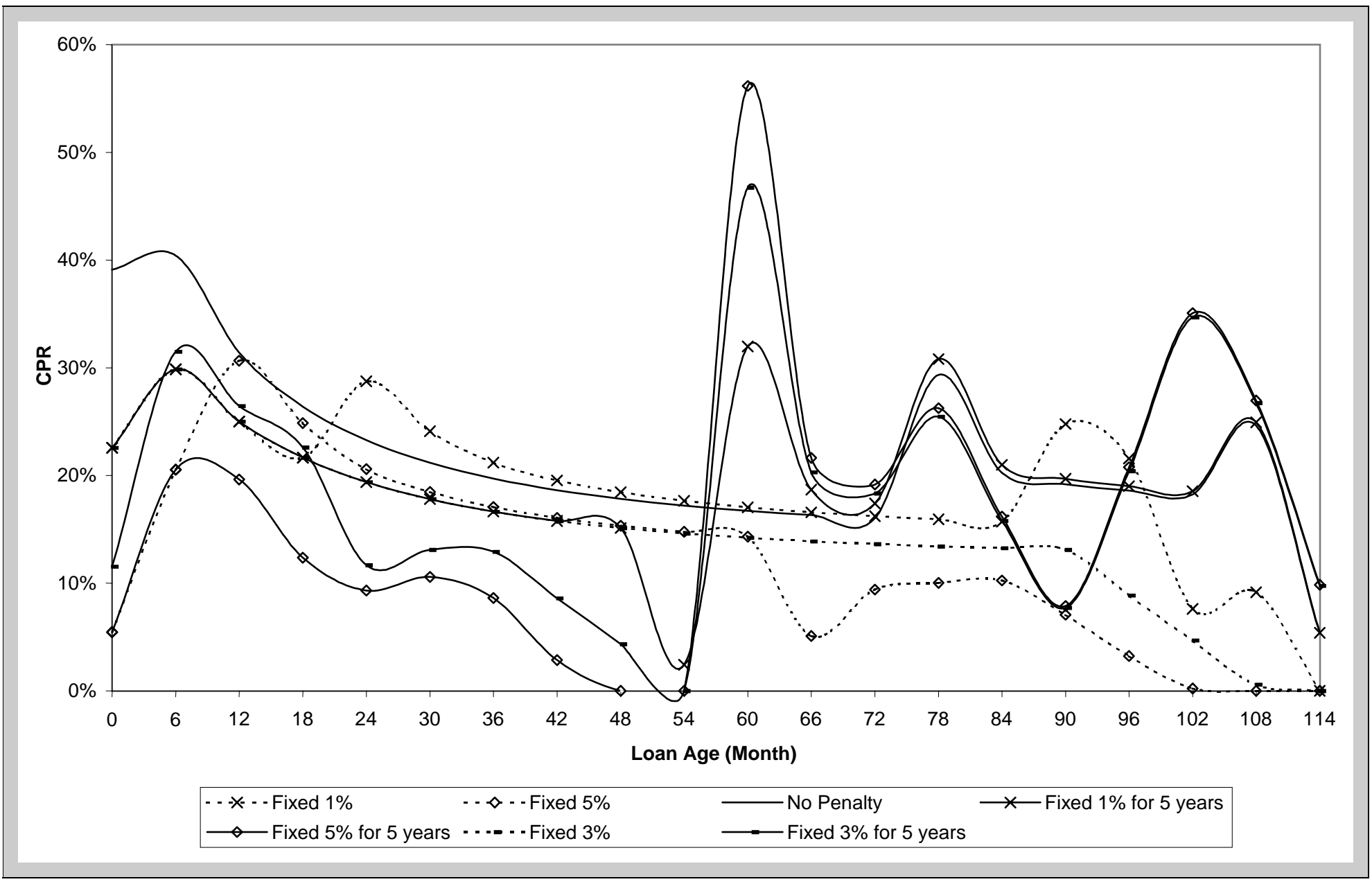


Exhibit 2 | Conditional Probability of Prepayment for Lockout Loans

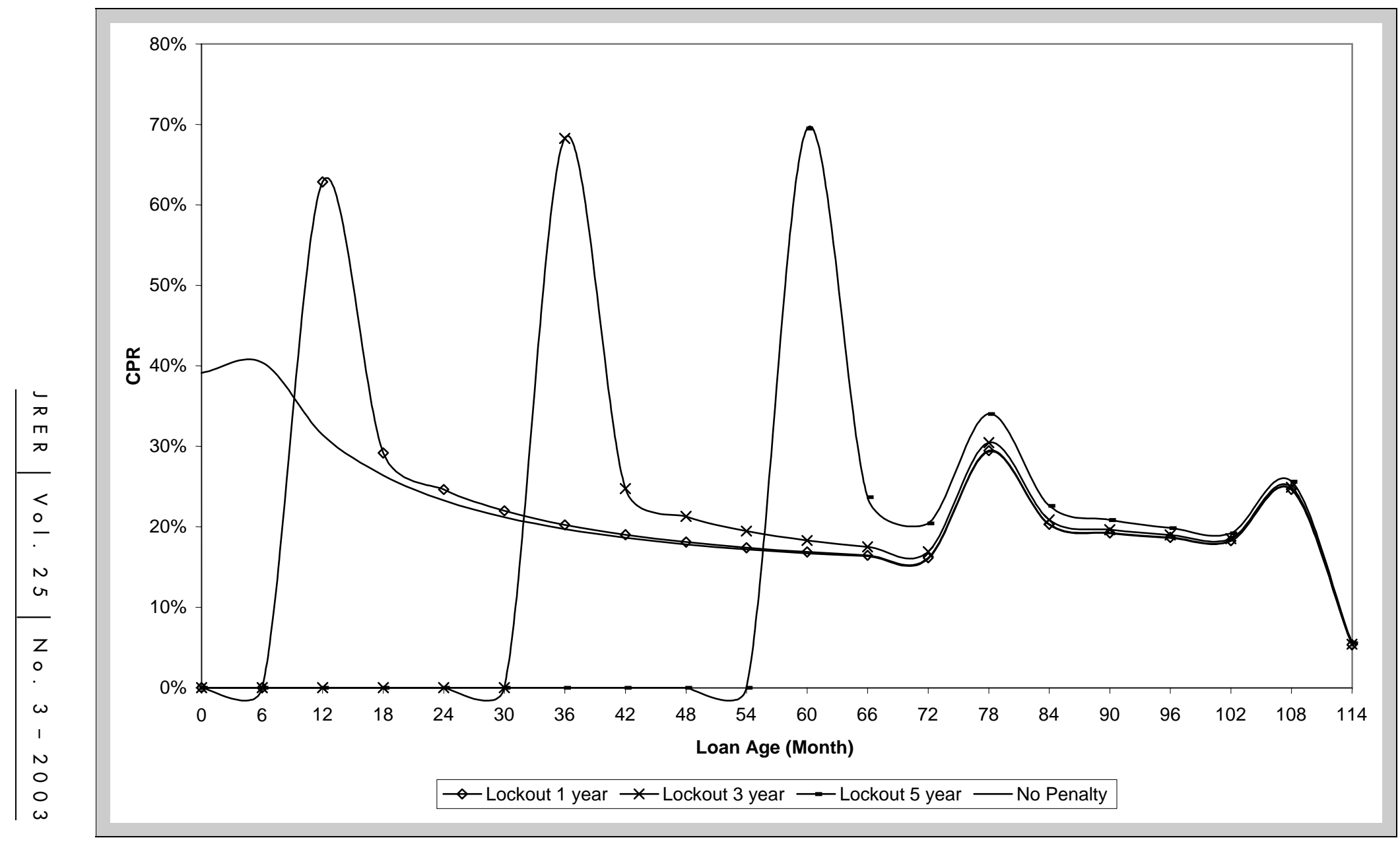


Exhibit 3 | Conditional Probability of Prepayment for Step-down and Yield Maintenance Loans

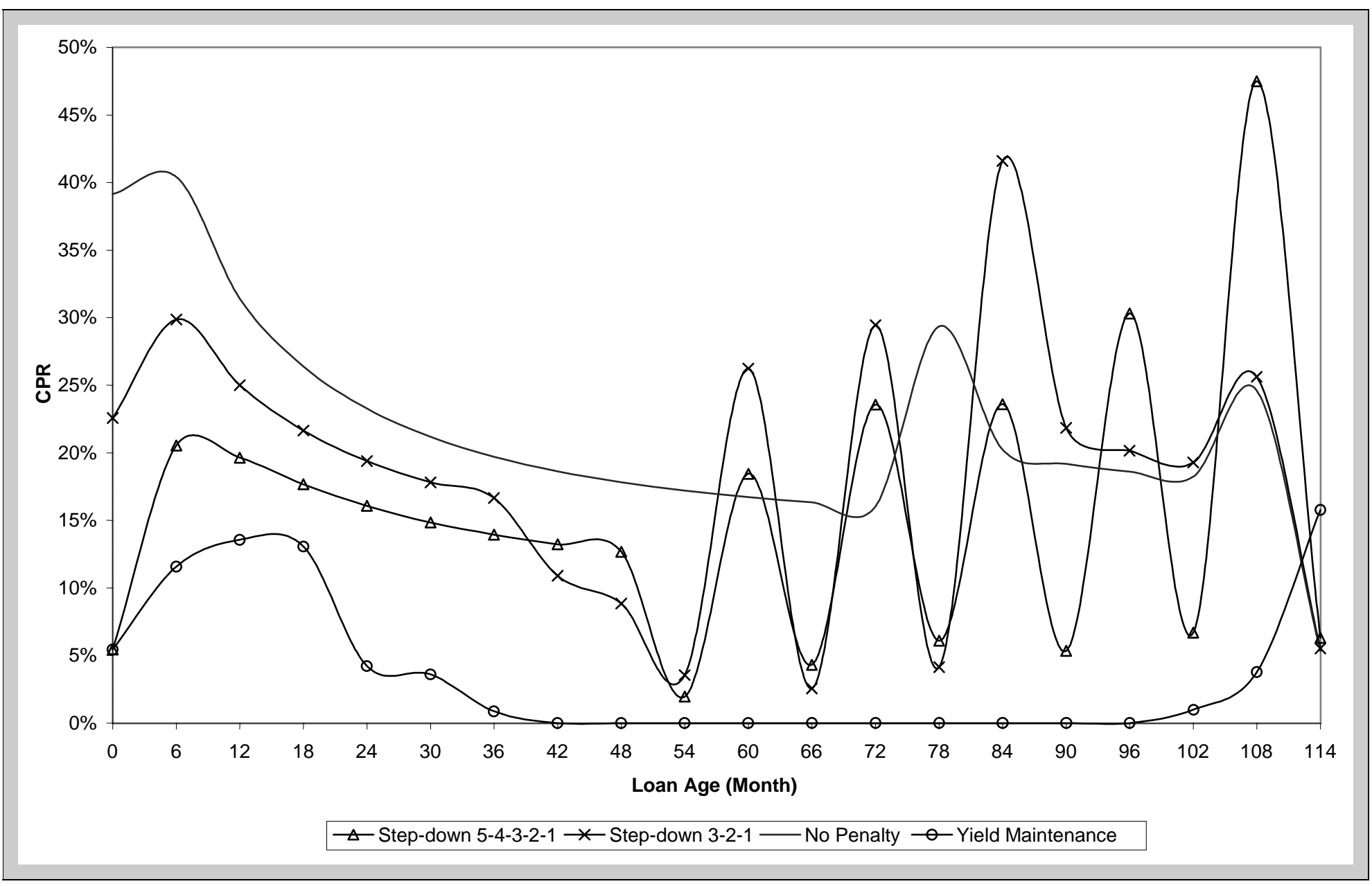


Exhibit 4 | Simulation of Alternative Prepayment Penalty Structures: Probability of Prepayment after 5 and 10 Years and Value of the Prepayment Option

\begin{tabular}{|c|c|c|c|}
\hline & \multicolumn{2}{|c|}{ Cumulative Probability of Prepayment } & \multirow{2}{*}{$\begin{array}{l}\text { Value of Prepayment } \\
\text { Option } \\
\text { (Discount from Par) (\%) }\end{array}$} \\
\hline & After 5 Years (\%) & After 10 Years (\%) & \\
\hline No Prepayment Penalty & 77.81 & 92.10 & 7.24 \\
\hline \multicolumn{4}{|l|}{$\begin{array}{l}\text { Fixed Prepayment Penalty } \\
\text { Over life of loan }\end{array}$} \\
\hline $5 \%$ & 64.32 & 73.93 & 2.95 \\
\hline $3 \%$ & 67.26 & 80.33 & 4.02 \\
\hline $1 \%$ & 72.89 & 87.77 & 5.18 \\
\hline \multicolumn{4}{|l|}{ Over 5 years } \\
\hline $5 \%$ & 38.28 & 85.71 & 4.83 \\
\hline $3 \%$ & 55.11 & 88.21 & 5.59 \\
\hline $1 \%$ & 64.94 & 89.25 & 6.63 \\
\hline \multicolumn{4}{|l|}{ Step-down After Five Years } \\
\hline $5-4-3-2-1-0 \%$ & 52.34 & 82.84 & 4.39 \\
\hline $3-2-1-0 \%$ & 62.84 & 88.22 & 5.04 \\
\hline \multicolumn{4}{|l|}{ Lockout } \\
\hline Over life of loan & 0 & 0 & 0.00 \\
\hline Over 5 years & 0 & 81.55 & 3.91 \\
\hline Over 3 years & 61.10 & 86.74 & 4.66 \\
\hline Over 1 year & 74.00 & 90.79 & 5.71 \\
\hline Yield Maintenance & 24.18 & 32.07 & 0.07 \\
\hline
\end{tabular}

6. Finally, the yield maintenance formula used in the simulations is found to be quite effective, both at lowering the exercise of prepayment and especially at lowering the value of the prepayment option. Prepayment occurs only over the first forty-eight months of loan life and between month 108 and the end of term, and the maximum rate is only about $14 \%$. Exhibit 4 confirms that yield maintenance has the lowest cumulative prepayment rate and lowest option value among penalty designs evaluated, except for lockouts.

The simulation results are generally consistent with the results of Kelly and Slawson (2001), particularly the reduction in prepayment before the "cliff" of penalty reduction, followed by an increase after the reduction or elimination of 
the penalty, and the sawtooth pattern resulting from the step-down structure. This is interesting, since a relatively simpler simulation process is used and default excluded. One interpretation would be that regardless of the analytic method used, prepayment penalties matter and time-varying penalties affect matter the most.

Other results include the effectiveness of yield maintenance formulation in controlling prepayment and reducing its impact on pricing. They also reveal expected effects of various covariates on prepayment over time, including the parameters associated with penalty design, other mortgage terms and macroeconomic variables that can motivate prepayment.

The Empirical Model: Specification

The simulations described suggest the following variables for inclusion in the empirical model.

1. The level of the contract rate on the loan relative to the current market rate and the present value of savings on refinancing, net of penalty costs;

2. The expected trend in mortgage rates, proxied by the shape of the yield curve;

3. The expected volatility of mortgage rates;

4. The level of the current prepayment penalty;

5. The remaining term on the mortgage;

6. The outstanding balance on the loan at the end of term as a fraction of original loan balance;

7. "Burnout," or the extent to which the loan has already been exposed to positive refinancingincentives;

8. The prepayment penalty "type, and related characteristics;

9. The remaining term(s) until any reduction(s) in the current prepayment penalty;

10. The magnitude of expected reduction(s) in the current prepayment penalty; and

11. Uncertainty in the level(s) of future prepayment penalties.

These time-varying covariates relate to the pure options framework and do not include other factors that may be influential but arise outside of the pure options framework. Such variables may be associated with transaction costs, factors influencing borrower demand or information asymmetries. They may relate to the property, the borrower or the lender, as well as the loan terms and the macroeconomic environment. Those that have been identified in the literature on multifamily prepayment previously discussed include: 
12. The current loan-to-value ratio;

13. The expected trend in the future loan-to-value ratio; and

14. Uncertainty with respect to the future loan-to-value ratio.

Variables (12) through (14) are primarily relevant to default. Since previous work (Kau, Keenan, Muller and Epperson, 1992) has shown the default option to be interrelated with the prepayment option in the sense that default is a form of prepayment and borrowers who would otherwise prepay may find it optimal to default if they are prevented from prepayment, it may be important to consider the default option, at least in a competing risks framework. LTV may also be important in prepayment from an institutional standpoint, since underwriting rules make refinancing high LTV loans difficult, especially if property values declines. This phenomenon has been documented in the single-family market (Green and LaCour-Little, 1999; and Mattey and Wallace, 1999a).

15. Seasoning, or elapsed time since origination.

This variable could represent a number of factors, including increasing or decreasing commitment or "attachment" to the investment over time ("attachment to neighborhood and the housing unit" has been shown to be important in single family prepayments), the increased probability of "trigger events" or the need to consume liquid assets to maintain the current investment.

\section{Seasonality.}

This variable could represent seasonally correlated trigger events that motivate sales or refinancings, such as end of the calendar, fiscal, or tax year, or the timing of quarterly reports, although it does not correspond directly to the seasonal patterns of household mobility that are evident in single family prepayment models.

17. Financial sophistication of the investor or information availability, proxied by loan size or networth of borrower;

18. Tax law changes, which could affect any of the option-theoretic or other variables influencing prepayment;

19. Borrower solvency, proxied by the contemporaneous debt-coverage ratio;

20. Type of borrower, which may proxy for borrower sophistication in recognizing prepayment advantages and knowledge of prepayment procedures;

21. Type of lender, which may proxy for the degree of aggressiveness in educating borrowers about prepayment opportunities relative to the aggressiveness of other lenders.

An analysis of these other external factors (items 17-21 above) will not occur here. Note, however, that although model default is not explicitly modeled, 
covariates are included that proxy for default risk, such as LTV in hazard model specification.

\section{A Proportional Hazards Model of Multifamily Prepayments}

Green and Shoven (1986) first applied the proportional hazard model to mortgages, and recent applications are numerous (e.g., Schwartz and Torous, 1992; Vandell, Barnes, Hartzell, Kraft and Wendt, 1993; Deng, 1995, 1997; Follain, Ondrich and Sinha, 1997; Mattey and Wallace, 1999; and Bennett, Peach and Peristiani, 2001). In hazard models, failure time $T$ (in mortgage modeling, failure time is the time to prepayment and/or default) has probability density distribution $f\left(T_{i}\right)$ and cumulative probability distribution $F\left(T_{i}\right)$. The hazard function $H\left(T_{i}\right)$ is defined as:

$$
H\left(T_{i}\right)=\lim _{t \rightarrow 0} \frac{\operatorname{Prob}\left(T_{i}<T<T_{i}+t \mid T \geq T_{i}\right)}{t}=\frac{f\left(T_{i}\right)}{1-F\left(T_{i}\right)}
$$

If time is measured in infinitely small discrete units, the hazard function is simply:

$$
H\left(T_{i}\right)=\operatorname{Prob}\left(T=T_{i} \mid T \geq T_{i}\right)=\frac{f\left(T_{i}\right)}{1-F\left(T_{i}\right)}
$$

Intuitively, the hazard rate is the probability of failure time being $T_{i}$, given the fact that the subject survives up to time $T_{i}$, or, roughly, the conditional probability of failure at time $T_{i}$.

Theoretically, the hazard function can take any functional form. One particular functional form that is widely used in mortgage modeling is Cox's proportional hazard specification. The hazard rate for subject $j$ at time $i$ is:

$$
H_{i j}\left(x_{i j} ; \beta\right)=H_{0}\left(x_{i}\right) \exp \left(x_{i j} \beta\right)
$$

In this specification, $H_{0}$ is the baseline hazard, i.e., the hazard rate if all covariates $x_{i j}$ are zero. In the mortgage literature, the baseline hazard is typically specified using either loan-age dummies or a polynomial function of loan age intended to capture the seasoning ramp. The baseline hazard is shifted by explanatory vector 
$x_{i j}$, which represents the mortgage characteristics or market conditions for mortgage $j$ at time $i$.

One advantage of using the proportional hazard model is that the $\beta$ coefficients can be estimated using Cox's partial likelihood method without specifying a baseline function. Thus, the effects of various prepayment penalties can be quantified on borrower's prepayment behaviors without having to assume any particular functional form of the baseline hazard itself. But to generate conditional prepayment predictions, the baseline hazard must be specified as well.

This is not a trivial exercise. Prentice and Gloeckler (1978), Han and Hausman (1990), Meyer (1990) and Sueyoshi (1992) propose semi-parametric methods that can estimate the baseline hazard and the $\beta$ coefficients simultaneously. But their methods are computationally demanding. Deng (1995) proposes a semi-parametric method that transforms the proportional hazard model into a system of seemingly unrelated regressions. His method can deal with competing risks and is computationally feasible for large data sets. This method involves group loans into relatively homogeneous cells and requires large amount of data.

Cox's partial likelihood method was selected to test the propositions embodied in the model specification above, focusing on the impact of various prepayment penalties on the prepayment hazard. This makes Cox's partial likelihood method especially desirable, since the estimates of the $\beta$ coefficients can be recovered without assuming a particular functional form for baseline hazard. Follain, Ondrich and Sinha (1997) attempt to extend the Cox model into a competing risks framework that recognizes the existence of possible failure due to both prepayment and default. However, since our data contains few defaults, the competing risk model estimates would be difficult, if not impossible, to estimate, especially when we are examining the timing, as well as the incidence, of events. Accordingly, we treat the small number of defaults as censored. Other research on prepayments in the single-family market has shown that when there are only a very small number of defaults, obtaining statistically significant results is unlikely (Ambrose and LaCour-Little, 2001). ${ }^{8}$

To recover the baseline hazard, a two-step limited information maximum likelihood method is applied. In the first step, the Cox's partial likelihood is performed to obtain the estimated $\hat{\beta}$ coefficients. In the second step, the baseline hazard is expressed as a function of mortgage age:

$$
H_{i j}\left(x_{i j} ; \beta\right)=H_{0}(\text { MortgageAge }) \exp \left(x_{i j} \hat{\beta}\right)
$$

where $\hat{\beta}$ is the estimated $\beta$ coefficients from the first step partial likelihood procedure. Notice that by substituting $\beta$ with $\hat{\beta}$, the term $\exp \left(x_{i j} \hat{\beta}\right)$ is now a known quantity. The baseline hazard can be estimated using the maximum likelihood method. The log likelihood function is: 


$$
\begin{aligned}
\log \text { likelihood }= & \sum_{\forall i} \sum_{\forall j}\left(I ( \text { Prepayment } ) * \operatorname { l o g } \left(H_{0}(\text { MortgageAge })\right.\right. \\
& \left.* \exp \left(x_{i j} \hat{\beta}\right)\right)+(1-I(\text { Prepayment })) \\
& \left.* \log \left(1-H_{0}(\text { MortgageAge }) * \exp \left(x_{i j} \hat{\beta}\right)\right)\right)
\end{aligned}
$$

where I(Prepayment) is an indicator variable equaling 1 if the mortgage was prepaid in month $j$ and 0 otherwise. Murphy and Topel (1985) show that the maximum likelihood estimators at the second step are consistent and asymptotically normal.

The seasoning ramp for multifamily mortgages has been little studied. ${ }^{9}$ Lacking a particular shape to the hazard function, the baseline hazard is modeled as a polynomial of mortgage age, allowing flexibility in functional forms:

$$
\begin{aligned}
H_{0}(\text { MortgageAge })= & \left(\alpha_{1} * \text { MortgageAge }+\alpha_{2} * \text { MortgageAge }^{2}\right. \\
& +\alpha_{3} * \text { MortgageAge } e^{3}
\end{aligned}
$$

This two-step estimation method can take full advantage of the desirable features of Cox's partial likelihood method. Computational simplicity is a further attraction.

As previously discussed, many argue that default and prepayment probabilities be jointly determined and thus be estimated simultaneously under a competing risk framework (e.g., Deng, 1995; and Deng, Quigley and Van Order, 2000). Those models assume a correlation structure in the error terms of prepayment and default equations. Computations are considerably more complicated. In our data set, default risk is very low (there are only 36 out of 1,165 loans defaulted during the study period). To address the competing risk issue, the variables influencing default (such as LTV, regional dummies) were incorporated into the prepayment equation, instead of modeling the competing risk explicitly through adding a default equation and a correlated error structure.

It has also been recognized that there is unobserved heterogeneity among borrowers. This heterogeneity is caused by the inability to identify all characteristics influencing prepayment behavior. Ignoring heterogeneity may bias parameter estimates. Unobserved heterogeneity is the source of "burnout" in prepayment modeling: two seemingly identical borrowers respond to identical prepayment incentive differently. Modeling "burnout" has been a very difficult job in prepayment modeling. Traditionally, it has been modeled ex post through measuring borrower's past response (or failure in responding) to refinancing opportunities. Another type of burnout modeling explicitly assumes a distribution 
of prepayment response functions among groups of borrowers [see Hall (2000) for a review]. In industry models, this approach is in a form of "multi-population model" (e.g., Hayre, 1994; Hayre, Chaudhary and Young, 2000; or Patruno, 1994). A typical multi-population model assumes the borrowers belong to several populations (in practice, it is usually fewer than three populations for computational simplicity). Populations are assumed to have different refinancing sensitivities. As the borrowers are exposed to refinancing opportunities, the borrowers in the more refinancing sensitive groups prepay faster than the less sensitive groups and exit the population earlier, leaving the whole population with larger composition of "slower" refinancers. The overall refinancing sensitivities of the population is thus lowered. With several exceptions, academic research on this class of model has been rare. Stanton (1995) assumes a continuous distribution of transaction costs among all borrowers and calibrates the distribution on the observed data. The calibrated transaction costs, however, are unreasonably high (about 40\%), which casts some doubt on an otherwise reasonable modeling approach. Deng, Quigley and Van Order (2000) assume 2-3 populations of borrowers in prepayment function. Deng and Quigley (2001) further extend the model in assuming a continuous distribution of borrower heterogeneity and incorporate a variable measuring a borrower's past failure in responding to refinancing opportunities into the distribution assumption of borrower heterogeneity. Both models show that unobserved heterogeneity exists and matters in prepayment modeling. The disadvantage of this multi/continuous population model, besides the great complexity involved, is that the choice of population is arbitrary, and there is no definitive evidence showing better performance relative to simpler approaches. Note that Ambrose and LaCour-Little (2000) employed the competing risk methodology controlling for unobserved heterogeneity and produced results qualitatively similar to simpler models without such controls. Accordingly, this study employs the simpler approach by simply including a measure of "burnout" equal to the cumulative sum of the past refinancing opportunities (constrained to zero during lockout period, if any).

\section{Data}

Data collection began with a loan level database of 2,573 multifamily mortgage loans serviced by a major loan-servicing firm that prefers anonymity. Loans were originated throughout the United States during the 1991-1996 period and initially observed through June 1998. Most are portfolio loans, not collateral for CMBS. Initially, loan servicing records were examined to extract origination date, termination date and time-of-origination loan characteristics, such as loan size and type, note rate and loan-to-value ratio. Since numerous characteristics of interest were not included on the loan servicing system, data was augmented by a detailed file-by-file review and included a $100 \%$ sample of terminated loans plus an equal number of randomly drawn still-active loans. This review allowed examination of important details about prepayment penalty structure. The information obtained included type of penalty (if any) and the formula for calculating the penalty over

\begin{tabular}{l|l|lll} 
J R E R & Vol. 25 & No. $3-2003$ \\
\hline
\end{tabular}


time. As in most data collection efforts, there were occasional missing values, which were assumed to be uninformative. After sampling, the final data set consisted of 1,165 loans, of which about half prepaid during the observation period. The mean note rate is $9.05 \%$ and the mean original loan amount is $\$ 725,000$. The relatively small original loan size indicates that many of these are smaller and older properties, as compared to large scale newly constructed suburban apartment complexes. ${ }^{10}$

Descriptive statistics for the sample appear in Exhibit 5. There is probably some sample selectivity at work here, since presumably borrowers (to the extent they can) choose prepayment penalty types that best match their expectations about holding period and future interest rate movements. It can be seen in Exhibit 5 that loans with yield maintenance penalties, for example, tend to be much larger than loans with fixed penalties. Perhaps more sophisticated borrowers with larger investment properties are more willing to accept strict and market rate dependent controls on their prepayment options, as compared to smaller investors, who prefer fixed and known limitations. In any event, the choice of contract and penalty type results from an unobservable bargaining process and the issue is not discussed further here. Penalty types are stratified in the hazard models in this study, so the results are conditional on the particular contract type selected (or bargained for) between borrower and lender.

After initial analysis of the data and a first draft of this article, the observation window was extended to April 2000. This had the effect of increasing the number of prepayments significantly, due in part to the drop in mortgage rates during late 1998. Since the sampling scheme was developed in April 1998, however, the data elements were re-weighted ${ }^{11}$ based on their prepayment status as of that point in time. A number of time-dependent variables were also added, including the refinancing incentive over time, loan age, remaining balance, percentage remaining balance, months until balloon or maturity, slope of the term structure, volatility of interest rates, and, of course, the amount of penalty due on refinancing at each point in time.

Prepayment models normally require some benchmark rate to be used as the "market rate." In single-family models, agency par yields or the Freddie Mac primary mortgage market survey rate are common choices. Since no obvious, similar benchmark for commercial loans was available, the mean rate for new commercial mortgages originated during the month and year of observation was used the measure of market rate. This seemed preferable to adding an arbitrarily chosen spread to Treasury rates and captures the time-varying mortgage-treasury yield spread.

Loans were grouped into the following categories based on prepayment penalty type: fixed, lockout, none, other, step down and yield maintenance. Most of the loans have lock-outs for some period of time, followed by fixed penalties (fixed as percentage of loan balance, therefore, declining over time as the loan balance amortizes). For stratification, step-down and yield maintenance penalty types were 
Exhibit 5 | Descriptive Statistics

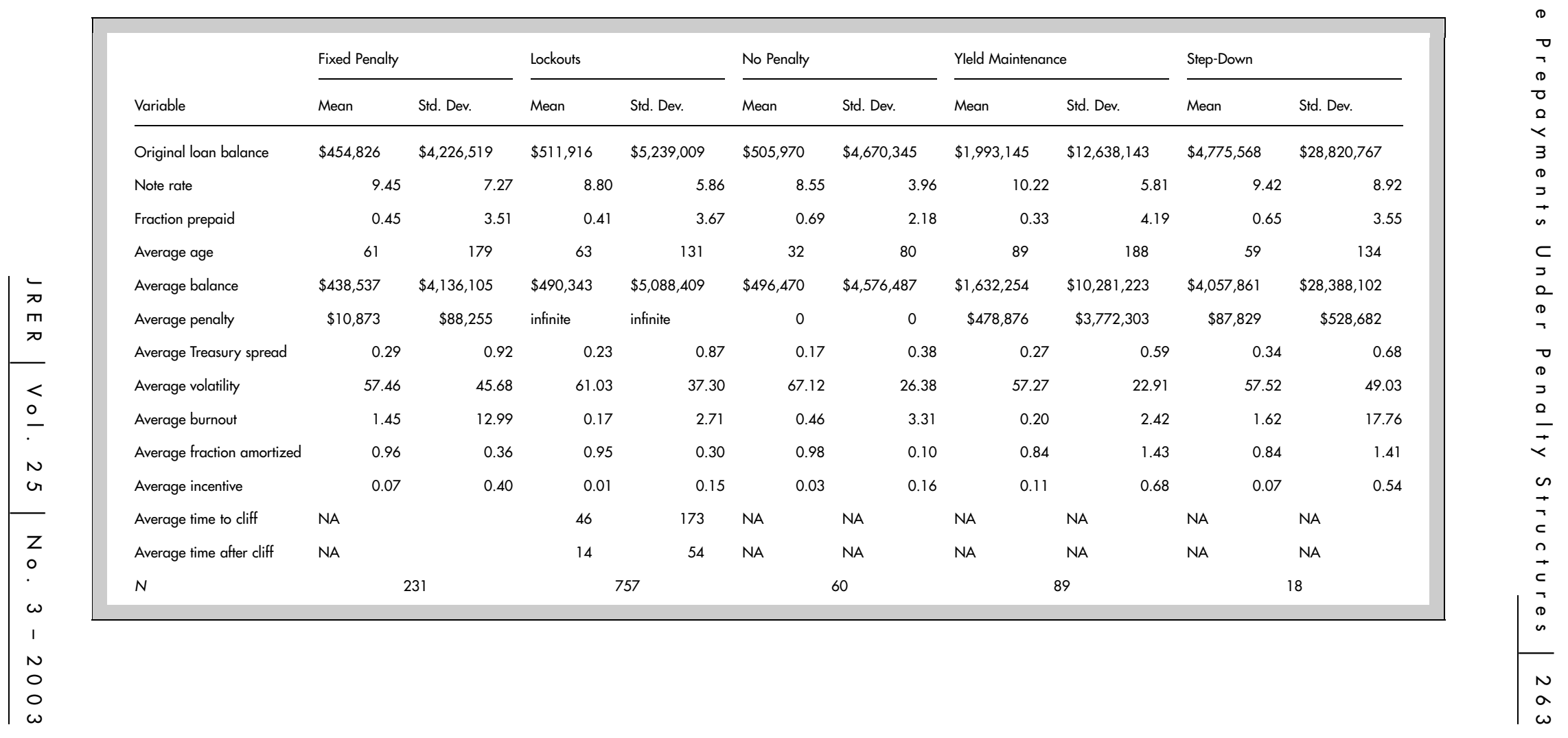


grouped together, since both types involve time-varying penalties that depend on more than just the current outstanding loan balance.

Exhibit 6 shows survival curves and cumulative prepayment hazard rates for the loan sample, stratified by penalty type. Note that these simple uncontrolled results support our priors based on simulations. Specifically, loans with no prepayment penalty prepay at the highest rate, while those with yield maintenance prepay the lowest rates. In general, loans with a fixed and step-down penalty formula have comparable survival rates, which are somewhat lower than those with lockouts. Of course, these uncontrolled results could be reflecting a variety of influences beyond differences in prepayment penalty types, such as prepayment penalty terms, the timing of originations, etc. Identification of the prepayment penalty effects in isolation requires the hazard model.

Results

Four versions of the proportional hazard model were estimated: first combining all loans and using dummy variables to represent the various penalty types, followed by stratification of the data by penalty type, with slightly modified specifications to account for particular features of the individual penalty structures. The variables used in the models are defined in Exhibit 7.

Results for the entire sample appear in Exhibit 8. There were a total of 1,165 loans of which $626(54 \%)$ prepaid during the observation period, equivalent to roughly a $14 \%$ constant prepayment rate over an average loan age of five years. To focus on the effect of penalty type per se, dummy variables were included for each while the relative magnitude of the penalty appears in the variable REFIINC as a transaction cost. Loans with no prepayment penalty represent the omitted category. The Midwest region (the largest group of loans) is the omitted region. Generally, signs of coefficients are as expected.

The refinancing incentive net of prepayment penalty costs (REFIINC) is positive and highly statistically significant, consistent with option theory. Interest rate volatility (VOLATL) is negative and highly statistically significant, consistent with the value of delay implied by option theory. The presence of a balloon payment within one year (BALLONE) is positive and highly significant. Loan size $(O R I B A L)$ is positive and statistically significant and burnout (BURNOUT) is negative and statistically significant. The slope of the yield curve (TSPREAD) and original loan to value ratio (LOANVAL) are both positive but not statistically significant. The regional dummies for WEST and NE are negative and statistically significantly, possibly because of lingering problems with commercial property markets in those areas during the early 1990s.

Turning to penalty type, loans with any prepayment penalty display significantly lower rates of prepayment than loans with no penalty. Among prepayment penalty types, yield maintenance loans exhibit the lowest prepayment rates with a risk ratio of 0.15 (all risk ratio comparisons here are relative to no prepayment 
Exhibit 6 | Cumulative Survival Probability

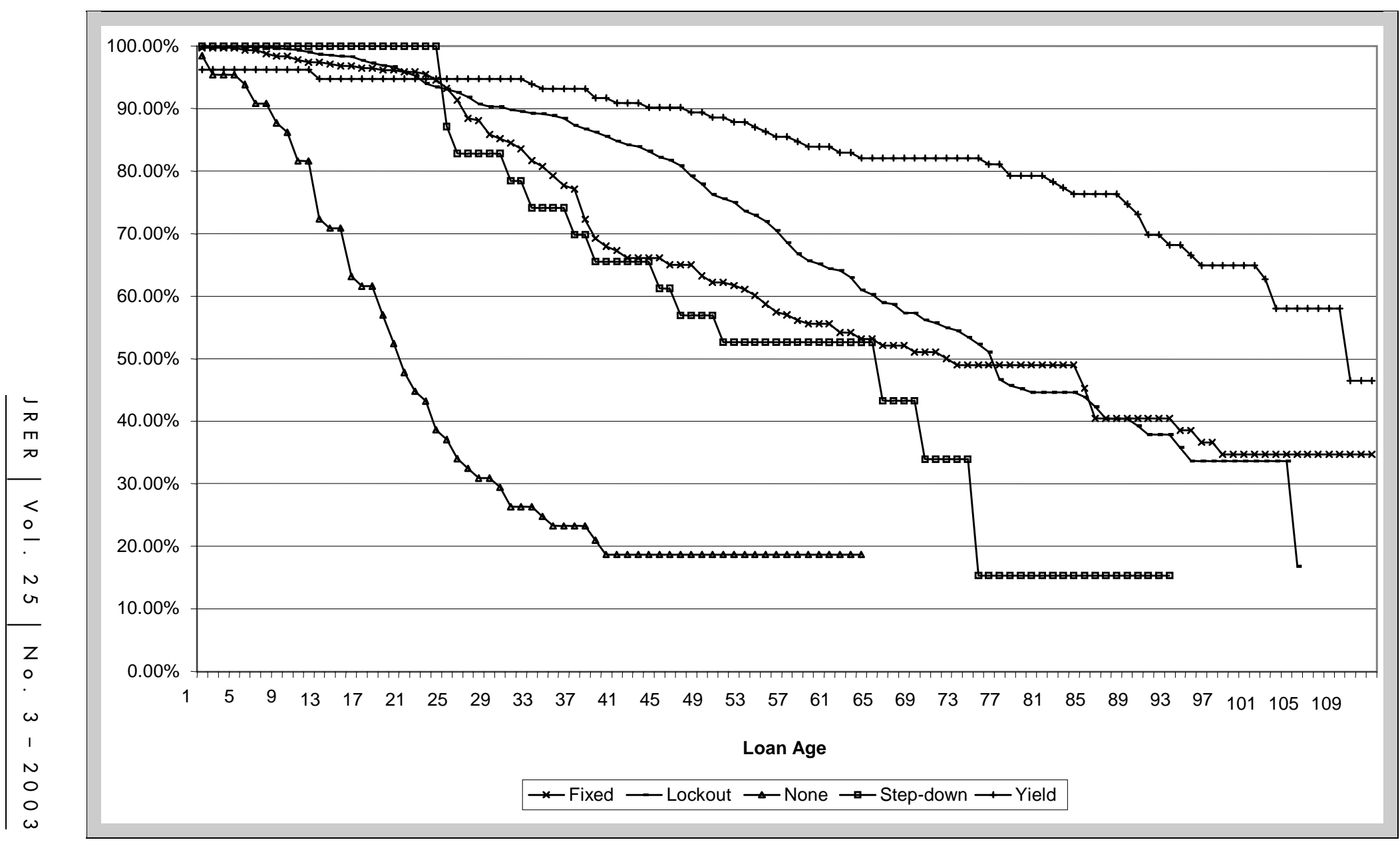


Exhibit 7 | Variable Definitions

ORIBAL: Original loan balance.

RMBALRT: Remaining loan balance ratio = remaining loan balance/original loan balance.

REFINC: The refinancing incentive, defined as the present value of savings less refinancing costs. The refinancing incentive is calculated as [PV(remaining payments at market rate)/remaining balance - 1]. Refinancing costs are the ratio of the prepayment penalty over the remaining balance. For lockout loans during lockout period, REFINC is set to zero, since prepayments are strictly prohibited.

BURNOUT: BURNOUT $T_{t}=\sum_{i=1}^{t-1} \max \left(R E F I N C_{i}\right.$, 0$)$, i.e., the accumulated non-negative incentive.

TSPREAD: Yield curve slope $=\mathrm{LN}$ (10-year Treasury rate/1-year Treasury rate).

VOLATL: Interest rate volatility $=\operatorname{SQRT}(12)^{*} \operatorname{STD}(C M T 10(t)-C M T 10(t-1)$, where STD is the standard deviation function. SQRT(12) scales the volatility to annual numbers assuming an independent interest rate generating process.

LOANVAL: Original loan-to-value ratio.

BALLONE: Indicator variable equaling one if the mortgage is within one year of the maturity, and zero otherwise. Most contracts eliminate penalties during the final year prior to balloon to facilitate sale, refinancing and/or renegotiation of loan terms.

WEST: Indicator variable equaling one if the property is located within the West region, zero otherwise.

NE: Indicator variable equaling one if the property is located within the Northeast region, zero otherwise.

SE: Indicator variable equaling one if the property is located within the Southeast region, zero otherwise.

REST: Indicator variable equaling one if the property is located outside the West, Northeast, Southeast or Midwest regions, zero otherwise.

YIELD: Indicator variable equaling one if the mortgage has a yield maintenance prepayment penalty, zero otherwise.

FIXED: Indicator variable equaling one if the mortgage has a fixed prepayment penalty, zero otherwise.

STEP-DOWN: Indicator variable equaling one if the mortgage has a step-down prepayment penalty, zero otherwise.

LOCKOUT: Indicator variable equaling one if the mortgage has a lockout provision, zero otherwise. For estimation, this variable is further segmented into LOCKON1 (equal to 1 if the loan is in the lockout period and zero otherwise) and LOCKOFI (equal to 1 if the lockout period has expired).

OTHER: Indicator variable equaling one if the mortgage has a prepayment penalty other than listed above, zero otherwise.

TMTOCLI: "Time to cliff" = number of months left in the lockout period for loans with lockout provisions, zero if outside lockout period.

TMAFCLI: "Time after cliff" = number of months after the loan is outside the lockout period, zero if within lockout period.

PENALRT: Prepayment penalty as a fraction of unpaid loan balance.

REL_PEN: Relative penalty = difference between PENALRT and the minimum PENALRT in the next three years for loans with step-down or yield maintenance penalties. 
Exhibit 8 | Proportional Hazard Model of Time to Prepayment

\begin{tabular}{lllc|}
\hline Variable & Parameter Estimate & Std. Err & Wald Chi-Square \\
\hline ORIBAL & $1.2 \mathrm{E}-07$ & $2.9 \mathrm{E}-08$ & 16.7 \\
RMBALRT & -0.13 & 0.37 & 0.1 \\
REFINC & 6.65 & 0.95 & 49.4 \\
BURNOUT & -0.07 & 0.03 & 4.3 \\
TSPREAD & 0.47 & 0.33 & 2.0 \\
VOLATL & -0.06 & 0.00 & 228.4 \\
LOANVAL & $9.9 \mathrm{E}-04$ & $3.1 \mathrm{E}-03$ & 0.1 \\
BALLONE & 0.57 & 0.10 & 32.3 \\
WEST & -0.64 & 0.13 & 25.9 \\
NE & -0.84 & 0.17 & 24.4 \\
SE & -0.20 & 0.18 & 1.1 \\
REST & -0.33 & 0.12 & 7.4 \\
YIELD & -1.91 & 0.19 & 99.5 \\
FIXED & -1.38 & 0.15 & 88.8 \\
STEPDOWN & -1.31 & 0.32 & 16.2 \\
LOCKON1 & -1.76 & 0.14 & 154.5 \\
LOCKOF1 & -0.98 & 0.17 & 34.6 \\
\hline Notes: For all mortgages, the dummy variable is property type. N & & \\
628.0. & & & \\
& & & \\
\end{tabular}

penalty). The next lowest was loans with lockout provisions with a risk ratio of 0.17 (during the lockout period, i.e., when $L O C K O N 1=1$; such loans would have a risk ratio of 0.38 after expiration of the lockout period, i.e., when $L O C K O F 1=1$ ). Finally, step-down and fixed penalty loans have comparable risk ratios of 0.27 and 0.25 , respectively.

This data was also used to estimate the baseline hazard function, using a functional form of $\left(a x\right.$ age $\left.+b x a g e^{2}+c x a g e^{3}\right)$, as discussed above. There are totally 63,558 loan-month observations. The Newton-Raphson method was used to extract the maximum-likelihood estimates. The results are shown in Exhibit $10 .{ }^{12}$ Predicted prepayment speeds (CPR) are plotted in Exhibit 11 for an "average" fixed penalty mortgage in the data set (see Exhibit 5). This average mortgage has an original balance of $\$ 455,000$, a remaining balance of $\$ 438,000$, a $7 \%$ refinancing incentive, no burnout, 57.46 volatility, $70 \%$ LTV, more than one year before the balloon date and is located in the Northeast. The baseline hazard shows a seasoning ramp peak at around three years. 
Exhibit 9 | Stratified by Penally Type

\begin{tabular}{|c|c|c|c|c|c|c|c|c|c|}
\hline \multirow[b]{3}{*}{ Variable } & \multicolumn{2}{|l|}{ Lockouts } & \multirow[b]{3}{*}{ Wald Chi-Square } & \multicolumn{2}{|c|}{ Fixed Penalty } & \multirow[b]{3}{*}{ Wald Chi-Square } & \multicolumn{2}{|c|}{ Variable Penalty } & \multirow[b]{3}{*}{ Wald Chi-Square } \\
\hline & Parameter & & & Parameter & & & Paramater & & \\
\hline & Estimate & Std. Err. & & Estimate & Std. Err & & Estimate & Std. Err & \\
\hline ORIBAL & $2.0 \mathrm{E}-07$ & 4.1E-08 & 22.9 & $1.4 \mathrm{E}-07$ & $6.2 \mathrm{E}-08$ & 5.4 & 6.7E-09 & $5.0 \mathrm{E}-08$ & $1.8 \mathrm{E}-02$ \\
\hline RMBALRT & -1.77 & 0.79 & 5.0 & -1.54 & 0.92 & 2.8 & 0.14 & 0.80 & $2.9 \mathrm{E}-02$ \\
\hline REFIINC & 3.87 & 1.60 & 5.8 & 15.76 & 1.93 & 67.0 & 7.74 & 3.54 & 4.8 \\
\hline BURNOUT & 0.21 & 0.09 & 4.8 & -0.38 & 0.06 & 35.5 & -0.17 & 0.08 & 4.2 \\
\hline TSPREAD & 0.16 & 0.59 & 0.1 & 0.83 & 0.62 & 1.8 & 5.16 & 1.72 & 9.0 \\
\hline VOLATL & -0.11 & 0.01 & 365.3 & 0.03 & 0.01 & 11.6 & 0.14 & 0.03 & 22.6 \\
\hline LOANVAL & -0.01 & $4.2 \mathrm{E}-03$ & 2.2 & 0.00 & 0.01 & 0.1 & 0.01 & 0.01 & 1.7 \\
\hline BALLONE & 0.67 & 0.12 & 33.9 & 0.16 & 0.23 & 0.5 & 0.75 & 0.73 & 1.1 \\
\hline TMTOCLI & -0.07 & 0.01 & 97.9 & & & & & & \\
\hline TMAFCLI & 0.02 & 0.01 & 5.9 & & & & & & \\
\hline WEST & & & & -1.40 & 0.20 & 50.6 & 0.01 & 0.75 & 0.0 \\
\hline NE & & & & -1.04 & 0.30 & 12.4 & 0.74 & 0.61 & 1.5 \\
\hline FIXED & & & & -1.16 & 0.17 & 48.8 & & & \\
\hline RELPEN & & & & & & & 1.14 & 2.29 & 0.2 \\
\hline YIELD & & & & & & & -1.37 & 0.46 & 8.7 \\
\hline$-2 \log L$ & 726.8 & & & 210.1 & & & 61.8 & & \\
\hline$N$ & 757 & & & 291 & & & 107 & & \\
\hline
\end{tabular}


The next three proportional hazard models estimated use subsets of the data stratified by penalty type, with some minor changes to model specification depending on the particular sample. Exhibit 9 reports results: the first panel shows lockouts, the second fixed penalty and the third variable penalty. There were a total of 757 lockout mortgages, of which 385 (51\%) prepaid during the observation window. Since these loans were heavily concentrated in the Midwest, the regional dummies were excluded. To model the effect of time relative to expiration of the lockout period, the variables time-to-cliff (TMTOCLI), representing the number of months remaining in the lockout period (and equal to zero after expiration of the lockout), and time after cliff (TMAFCLI), the number of months after the expiration of the lockout (and equal zero if during the lockout period), were included. Estimated coefficients of these two variables are highly statistically significant although TMTOCLI is much larger in magnitude. Interpreting results, for each month farther the loan is from expiration of the lockout period, the hazard of prepayment declines by about $7 \%$.

Exhibit 9 shows that most of the variables independent of the penalty structure had similar effects as they did those in the aggregate sample containing all loans (Exhibit 8). For example, original loan size $(O R I B A L)$ is positive and significant in both Exhibit 8 and all panels of Exhibit 9. Likewise, refinancing incentive net of penalty costs (REFIINC) is positive and highly significant across all model specifications. Burnout has the wrong sign (positive) for LOCKOUT but this is attributable this to the coding, which does not allow burnout to accumulate during the lockout period. In Exhibit 8 and the other panels of Exhibit 9, burnout has the correct, negative sign.

The second panel of Exhibit 9 reports results for mortgages with no or fixed prepayment penalties (no prepayment penalty can be treated as a fixed penalty at rate zero). There were a total of 291 loans in this group, including 60 with no prepayment penalty. Over the observation period, $58 \%$ of those with fixed penalties prepaid while $87 \%$ of those with no penalty prepaid. Mortgages were concentrated in the Midwest, Northeast and West regions, so only two regional dummies were included. Again, REFIINC is the dominant factor, however in this regression volatility is positive (wrong sign) and statistically significant. The yield

Exhibit 10 | Baseline Hazard Estimation

\begin{tabular}{|c|c|c|c|}
\hline & Estimates & Std. Err. & T-Ratio \\
\hline Age & 6.70E-02 & 6.96E-03 & 9.63 \\
\hline Age $\wedge 2$ & $-1.23 \mathrm{E}-03$ & $2.26 \mathrm{E}-04$ & -5.43 \\
\hline Age $/ 3$ & $6.63 \mathrm{E}-06$ & $1.70 \mathrm{E}-06$ & 3.89 \\
\hline
\end{tabular}


Exhibit 11 | Baseline Hazard for an "Average" Loan

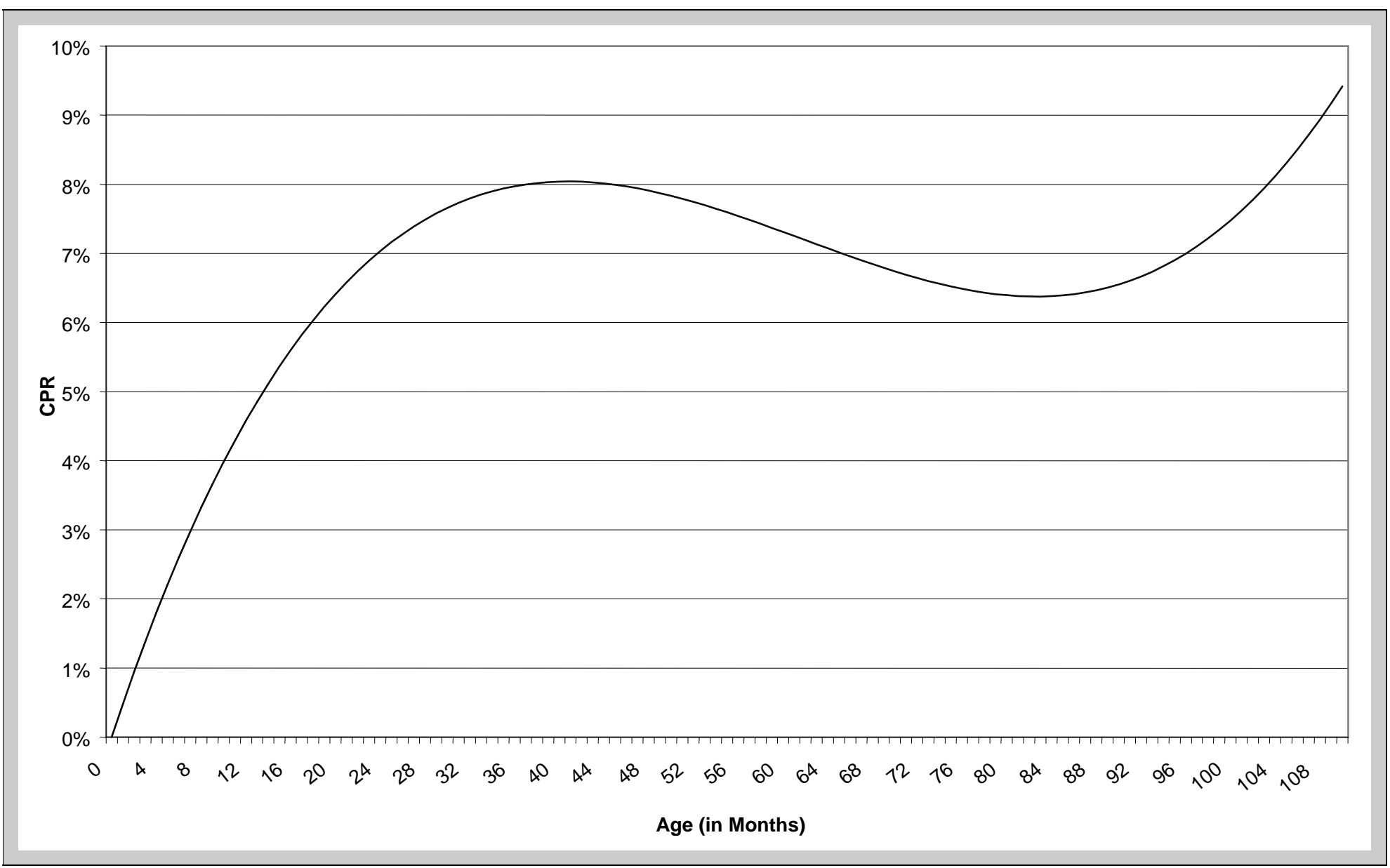


curve (TSPREAD) is not significant, nor is $L T V$, as in prior models. The signs on the regional dummies are the same as in prior models.

The third panel of Exhibit 9 shows the results for variable-prepayment-penalty mortgages, including step-down and yield maintenance. A total of 107 mortgages were in this category, with 50 of these $(47 \%)$ prepaying over the observation period. Probably due to the smaller sample size, many of the estimates are not statistically significant. However, in this model the slope of the yield curve $(T S P R E A D)$ is positive and statistically significant as is interest-rate volatility (VOLATL). A dummy variable YIELD was included to identify a yieldmaintenance loan, which was found to negative and highly statistically significant. The risk ratio of 0.25 (exponent of -1.37 ), relative to a step-down penalty, implies that yield maintenance penalties are highly effective in reducing prepayments.

\section{Conclusion}

This study finds strong confirmation that factors expected to affect multifamily mortgage prepayments do, in fact, conform to theory. Results are generally consistent with those of Kelley and Slawson (2001), namely, that time-varying penalty structure alters the value of delay and, hence, alters optimal refinancing. The dominant influences are those implied by option theory-the value of the option to refinance net of prepayment penalty costs, the approach of loan maturity or change in the magnitude of the penalty and rate volatility. Influences unrelated to the option-theoretic model such as region of the country, burnout and original loan size were also found to be significant.

The most salient findings, however, relate to the influence of prepayment penalty structure on hazard rates. Not only was there greater heterogeneity in the actual prepayment penalty structure than many assume, this heterogeneity was found to matter. There is clear evidence that the nature and terms of the prepayment penalty significantly affect the pattern of prepayment on multifamily mortgages and in a predictable fashion. Any penalty is helpful in reducing prepayments compared to no penalty. Yield maintenance and lockouts are the most effective among penalty types, consistent with option theory. ${ }^{13}$ Fixed and step-down penalties are less effective, but still important. Prepayments were found to decline on lockoutpenalty loans as time approaches the "cliff" of penalty termination and to rise immediately after the cliff to a peak, dropping again later, in conformance with theory. The level of the penalty rate as a fraction of remaining loan balance is highly significant in discouraging prepayment on notes with fixed penalties. Finally, with step-down penalties, the rate of decline in the penalty over time is significant. Both results are consistent with expectations from option theory and numerical results from our simplified simulations.

There are additional prepayment patterns predicted in the simulations that were not tested, but the existing evidence is sufficient to conclude that penalty structure matters and that penalties vary both in type and effect. Both results debunk the 
conventional wisdom-it is only default that matters in pricing commercial mortgages and mortgage-backed securities. Investors in CMBS products should pay close attention to the actual prepayment penalty structure, for "the devil is in the detail," as the saying goes. Lenders offering comparatively weaker penalty structures should price up at levels reflecting the increase prepayment risk. Effective pricing models must consider both the presence and structure of prepayment penalties.

\section{Endnotes}

1 Annual CMBS issuance grew from $\$ 19.0$ in 1995 to $\$ 78.3$ billion in 1998 , declining after the turmoil of late 1998 to $\$ 65.2$ billion during 1999 (Wheeler, 2000).

2 Kelley and Slawson (2001), page 251.

${ }^{3}$ Some argue that because default and prepayment are substitutes, it is essential to model them in a competing risk framework. While we agree with this position in theory, there is no generally accepted way to simulate the property price diffusion process in the multifamily market, since property values vary with rental and vacancy rates, levels and trends in operating expense, management and other factors. In contrast, prepayments vary mainly with interest rates. Moreover, in our empirical data, defaults are de minimus (approximately a 3\% cumulative default rate versus a 54\% cumulative prepayment rate). Ambrose and Lacour-Little (2001) find that with a similar level of default presence, applying a competing-risks framework has little impact on the empirical results.

${ }^{4}$ For the details of constructing binomial trees to simulate the CIR interest rate process, see Deng (1997).

5 We are indebted to Tony Sanders for providing these results to us.

${ }^{6}$ There were 36 defaults out of 1,165 loans in the data set. This represents a $3 \%$ cumulative default rate, as compared to a $54 \%$ cumulative prepayment rate. For purposes of the hazard model, defaulting loans remain at risk of prepayment up until default and are treated as censored thereafter.

7 Of course, if the default option were permitted, strict enforcement of the lockout clause would cause an increase in the likelihood of default and in the value of the default option under those conditions in which rates have dropped considerably and property values have not risen significantly. A borrower in these circumstances could find the losses associated with continuing to pay on an above-market note greater than the losses incurred by loss of one's equity in the home. See Kau, Keenan, Muller and Epperson (1992) for a good discussion of the interaction of the prepayment and the default options.

${ }^{8}$. Ambrose and LaCour-Little (2001) used a data set containing 2,699 ARM loans, of which $78.6 \%$ prepaid but only $1.6 \%$ defaulted. In their regression results using the Deng, Quigley and Van Order (2000) competing risk model, none of the results in the default function were statistically significant.

9 A recent study by Follain, Huang and Ondrich (1999) is an exception. The authors apply a specification for the baseline hazard function similar to those in this study with similar results as to the resulting shape after estimation.

${ }^{10}$ Financing this sort of property is of increasing interest to the GSEs, given their congressionally mandated affordable housing goals. 
11 Re-weighting is required due to the stratified sampling scheme, in which the event of interest, namely prepayment, is over-sampled relative to the non-event.

12 During the estimation, the product of baseline hazard and proportional hazard were bounded to be within zero and one.

13 As of this writing, underwriters at SalomonSmithBarney tell us that full-term lock-outs are the industry norm on new CMBS issues. However, one of the authors recently secured a small commercial mortgage from Bank of America scheduled to be sold into a CMBS conduit that contained a step-down penalty structure over a 10 -year term. We note in passing that the recently bankrupt Criimi Mae reportedly used step-down prepayment penalties frequently.

\section{References}

Ambrose, B. W. and M. LaCour-Little, Prepayment Risk in Adjustable Rate Mortgages Subject to Initial Year Discounts: Some New Evidence, Real Estate Economics, 2001, 29: 2, 305-28.

Abraham, J. M. and S. Theobald, A Simple Prepayment Model of Commercial Mortgages, Journal of Housing Economics, 1997, 6, 31-59.

Bennett, P., R. Peach and S. Peristiani, Structural Change in the Mortgage Market and the Propensity to Refinance, Journal of Money, Credit, and Banking, 2001, 33:4, 955-75.

Boyer, L. G., J. R. Follain, J. Ondrich and R. Piccirillo, A Hazard Model of Prepayment and Claim Rates for FHA Insured Multifamily Mortgages, Paper presented at the AREUEA Annual Meeting, January 1997.

Capone, C. A., Jr. and L. Goldberg, Motivating and Modeling Multifamily Mortgage Prepayment Rates, Paper presented at the AREUEA Annual Meeting, January 1998.

Chan, K. C., A. Karolyi, F. Longstaff and A. Sanders, An Empirical Comparison of Alternative Models of the Short-Term Interest Rate, Journal of Finance, 1992, 47:3, 120927.

Cheng, D., A. R. Cooper and J. Huang, Understanding Prepayments in CMBS Deals, In F. Fabozzi, et al., (Eds.), The Handbook of Nonagency Mortgage-Backed Securities, Frank J. Fabozzi Associates, 1997.

Cox, J., J. Ingersoll, Jr. and S. Ross, A Theory of the Term Structure of Interest Rates, Econometrica, 1985, 53:2, 385-407.

Daingerfield, E., Multifamily Project Securities, In F. Fabozzi et al., (Eds.), The Handbook of Mortgage-Backed Securities, Fourth edition, Chicago, IL: Probus Publishing, 1995.

Deng, Y., The Contingent Claims and Competing Risks For Mortgage Termination by Prepayment and Default, Ph.D. Dissertation, University of California-Berkley, 1995.

—., Mortgage Termination: An Empirical Hazard Model with a Stochastic Term Structure, Journal of Real Estate Finance and Economics, 1997, 14:3, 309-31.

Deng, Y. and J. M. Quigley, Woodhead Behavior and the Pricing of Residential Mortgages, Paper presented at the 2001 AFA-AREUEA joint session.

Deng, Y., J. M. Quigley and R. Van Order, Mortgage Terminations, Heterogeneity and the Exercise of Mortgage Options, Econometrica, 2000, 68:2, 275-307.

Elmer, P. J. and A. E. Haidorfer, Prepayments of Multifamily Mortgage-Backed Securities, The Journal of Fixed Income, 1997, 6:4, 50-63.

\begin{tabular}{l|l|l|ll} 
JRER & Vol. 25 & No. $3-2003$ \\
\hline
\end{tabular}


Follain, J. R., W-V. Huang and J. Ondrich, Stay, Pay or Walk Away: A Hazard Rate Analysis of FHA-Insured Multifamily Mortgage Terminations, Paper presented at AREUEA Annual Meeting, January 1999.

Follain, J. R., J. Ondrich and G. Sinha, Ruthless Prepayment? Evidence from Multifamily Mortgages, Journal of Urban Economics, 1997, 41, 78-101.

Foster, C. and R. Van Order, FHA Terminations: A Prelude to Rational Mortgage Pricing, Journal of the American Real Estate and Urban Economics Association, 1985, 13:3, 27391.

Goldberg, L. and C. A. Capone, Jr., Motivation and Testing of a Double-Trigger Hypothesis for Multifamily Loan Defaults, Unpublished manuscript, Office of Federal Housing Enterprise Oversight: Washington, DC, 1997.

Green, R. K. and M. LaCour-Little, Some Truths About Ostriches: Who Doesn't Prepay Their Mortgage and Why They Don't, Journal of Housing Economics, 1999, 8, 233-48.

Green, J. and J. B. Shoven, The Effects of Interest Rates on Mortgage Prepayments, Journal of Money, Credit, and Banking, 1986, 18:1, 41-59.

Hall, A., Controlling for Burnout in Estimating Mortgage Prepayment Models, Journal of Housing Economics, 2000, 9:4, 215-32.

Han, A. and J. A. Hausman, Flexible Parametric Estimation of Duration and Competing Risk Models, Journal of Applied Econometrics, 1990, 5: 1-28.

Hayre, L., A Simple Statistical Framework for Modeling Burnout and Refinancing Behavior, Journal of Fixed Income, 1994, 4:3, 69-55.

Hayre, L., S. Chaudhary, and R. Young, Anatomy of Prepayments, Journal of Fixed Income, 2000, 10:1, 19-49.

Kau, J. B. and T. Kim, Waiting to Default: The Value of Delay, Real Estate Economics, 1994, 22:3, 539-51.

Kau, J. B., D. C. Keenan, W. J. Muller and J. F. Epperson, Pricing Commercial Mortgages and Their Mortgage-Backed Securities, Journal of Real Estate Finance and Economics, 1990, 3:4, 333-56.

_., A Generalized Valuation Model for Fixed-Rate Residential Mortgages, Journal of Money, Credit, and Banking, 1992, 24:3, 279-99.

Kelly, A. and V. C. Slawson, Time-Varying Mortgage Prepayment Penalties, Journal of Real Estate Finance and Economics, 2001, 23:2, 235-54.

Mattey, J. and N. Wallace, Housing Price Cycles and Prepayment Rates of U.S. Mortgage Pools, Paper presented at the AREUEA Annual Meeting, January 1999.

Maxam, C. L. and J. D. Fisher, Pricing Commercial Mortgage Backed Securities, Paper read at the AREUEA Annual Meeting, January 1998.

Meyer, B. D., Unemployment Insurance and Unemployment Spells, Econometrica, 1990, 58, 757-82, 1990.

Murphy, K. and R. Topel, Estimation and Inference in "Two-Step" Econometric Models, Journal of Business and Economic Statistics, 1985, 3, 370-80.

Patruno, G. N., Mortgage Prepayments: A New Model for a New Era, Goldman Sachs \& Co., 1994.

Peristiani, S., P. Bennett, G. Monsen, R. Peach and J. Raiff, Effects of Household Creditworthiness on Mortgage Refinancings, Federal Reserve Bank of New York, Economic Policy Review, 1997, July, 83-103. 
Prentice, R. L. and L. A. Gloeckler, Regression Analysis of Grouped Survival Data with Application to Breast Cancer Data, Biometrika, 1978, 34, 57-67.

Quigley, J. and R. Van Order, Efficiency in the Mortgage Market: The Borrower's Perspective, Journal of the American Real Estate and Urban Economics Association, 1990, $18: 3,237-52$.

-., Explicit Tests of Contingent Claims Models of Mortgage Default, Journal of Real Estate Finance and Economics, 1995, 11:2, 99-117.

Riddiough, T. J. and H. R. Thompson, Commercial Mortgage Default Pricing with Unobservable Borrower Default Costs, Journal of the American Real Estate and Urban Economics Association, 1993, 21, 265-91.

Schwartz, E. S. and W. N. Torous, An Empirical Investigation of Mortgage Prepayment and Default Decisions, Working Paper, University of California-Los Angeles, 1992.

Stanton, H. R., Rational Prepayment and the Valuation of Mortgage-Backed Securities, Review of Financial Studies, 1995, 8:3, 677-708.

Sueyoshi, G., Semi-parametric Proportional Hazards Estimation of Competing Risks Models with Time-varying Covariates, Journal of Econometrics, 1992, 51:1-2, 25-58.

Tian, Y., A Simplified Binomial Approach to the Pricing of Interest-Rate Contingent Claims, Working paper, York University, 1992.

Titman, S. and W. Torous. Valuing Commercial Mortgages: An Empirical Investigation of the Contingent Claims Approach to Pricing Risky Debt, Journal of Finance, 1989, 44:2, 345-73.

Vandell, K. D., Predicting Commercial Mortgage Foreclosure Experience, Journal of the American Real Estate and Urban Economics Association, 1992, 20:1, 55-88.

—., How Ruthless is Mortgage Default? A Review and Synthesis of the Evidence, Journal of Housing Research, 1995, 2, 245-64.

Vandell, K., W. Barnes, D. Hartzell, D. Kraft and W. Wendt, Commercial Mortgage Defaults: Proportional Hazards Estimation Using Individual Loan Histories, Journal of the American Real Estate and Urban Economics Association, 1993, 21:4, 451-80.

Wheeler, D., The CMBS Market in the New Millennium, A publication of SalomonSmithBarney, New York, NY, 2000.

This research was funded by a grant from the Real Estate Research Institute. The authors wish to express their appreciation to the RERI for financial support, to Jenny Zhaohui Yu of the University of Wisconsin-Madison and Fuhat Sahin of Saint Louis University for research assistance, and to David Ling for advice and guidance. The views expressed are the authors alone and not necessarily those of Wells Fargo or of Fannie Mae.

Qiang Fu, Fannie Mae, Washington DC 20016 or qiang_fu@fanniemae.com.

Michael LaCour-Little, Wells Fargo Home Mortgage \& Washington University, Clayton, MO 63105 or michael.lacour-little@mortgage.wellsfargo.com.

Kerry D. Vandell, University of Wisconsin, Madison, WI 53706-1323 or kvandell@wisc.edu. 
